\title{
Editorial
}

\section{Selenium in the Treatment of Thyroid Diseases: An Element in Search of the Relevant Indications?}

\author{
Laszlo Hegedüs Steen J. Bonnema Kristian H. Winther \\ Department of Endocrinology and Metabolism, Odense University Hospital, Odense, Denmark
}

Selenium (Se) deficiency has been associated with a number of diseases [1], including thyroid diseases such as goiter, hypothyroidism, and autoimmune thyroiditis [2]. Se is an essential micronutrient that is incorporated into biologically active selenoproteins as the amino acid selenocysteine [3]. Among the most important are the iodothyronine deiodinases that are directly involved in thyroid hormone metabolism [3]. In healthy euthyroid individuals with marginal Se deficiency, Se supplementation has only minute, and clinically insignificant, effects on thyroid function [4]. However, Se levels have been found to be inversely correlated with thyroid size [5]. Furthermore, Se supplementation has been shown to decrease thyroid peroxidase antibodies (TPOAb) in autoimmune thyroiditis $[6,7]$. Accepting that chronic autoimmune thyroid diseases are multifactorial diseases, and that environmental triggers are key components in their etiology [8], it is no surprise that Se deficiency has come into focus. It could be speculated that the above constitutes, in part, the inspiration for the massive use of Se, as revealed by an Italian questionnaire study focusing on the therapeutic use of Se in some well-characterized clinical situations [9]. Despite the inherent reservations in using such a questionnaire study, the survey seems to show that a number of specialists have adopted routine Se therapy in disease entities where the evidence is, to put it mildly, questionable.

From a web-based survey of 1,888 Associazione Medici Endocrinologi (AME) members, 778 (41\%) provided responses to all 23 questions. The vast majority of specialists, of whom $>90 \%$ were endocrinologists, had used Se, and around $25 \%$ of them often or always. Let's look into the thyroid phenotypes investigated [9].

\section{Chronic Autoimmune Thyroiditis in Euthyroid Individuals}

While 3 out of 4 respondents (72\%) thought that there was evidence supporting Se use, 79\% prescribed it sometimes, often, or always. Half of those who prescribed Se (49\%) did it prophylactically to prevent serum TSH increase (49\%) or to decrease thyroid antibody levels (39\%). However, trials among individuals not receiving levothyroxine $\left(\mathrm{LT}_{4}\right)$ have not reported these effects [10]. 59\% of the respondents advocated use of $>100 \mu \mathrm{g}$ Se daily, without having knowledge of the pretherapy Se levels. Importantly, the scientific societies do not recommend Se supplementation for this indication.

\section{Hypothyroidism, with or without TPOAb}

In case of subclinical hypothyroidism and positive TPOAb, 2 out of 3 respondents would (sometimes, often, or always) suggest use of Se. In case of negative TPOAb this propensity would decrease to 1 in 3 respondents. The

\begin{tabular}{ll}
\hline KARGER & $\odot$ 2016 European Thyroid Association \\
& Published by S. Karger AG, Basel \\
E-Mail karger@karger.com & $2235-0640 / 16 / 0053-0149 \$ 39.50 / 0$ \\
www.karger.com/etj &
\end{tabular}

Prof. Laszlo Hegedüs, MD, DMSc

Department of Endocrinology and Metabolism, Odense University Hospital Kløvervænget 6, 6th floor

DK-5000 Odense C (Denmark)

E-Mail laszlo.hegedus@ rsyd.dk 
latter figures were also valid for hypothyroid individuals already on $\mathrm{LT}_{4}$. Systematic reviews and meta-analyses have shown that TPOAb levels, which we consider a surrogate activity marker, do decrease $[6,7]$ in patients receiving $\mathrm{LT}_{4}$ treatment. However, this practice is not endorsed by any specialist society.

\section{Chronic Autoimmune Thyroiditis and Pregnancy in Euthyroid Individuals}

Of the respondents who were proponents of Se use (40\%), their aim was to (in descending order): prevent development of hypothyroidism (40\%), reduce $\mathrm{TPOAb}$ levels (31\%), or prevent postpartum thyroiditis (25\%). Of the respondents who would suggest giving $>100 \mu \mathrm{g}$ Se daily $(70 \%), 10 \%$ would use a dose $>200 \mu \mathrm{g}$ daily. The latter could have deleterious effects when pretherapy Se levels are not known. Again, it is important to recognize that guidelines do not support this practice [11].

\section{Graves' Ophthalmopathy}

Given a case of a 42-year-old female with Graves' disease and no ophthalmopathy, $20 \%$ of the respondents would suggest adding Se to antithyroid drug therapy. In case she developed mild GO, 1 in 4 respondents would add $\mathrm{Se}$, and $50 \%$ of respondents would continue with $\mathrm{Se}$ also after remission of her Graves' hyperthyroidism. Based on a single study by Marcocci et al. [12], which showed significantly improved quality of life, reduced eye involvement, and improved clinical activity score in the Se group, the European Thyroid Association suggests a 6-month trial of Se in patients with mild GO [13]. While some have found lower Se levels in Graves' hyperthyroidism with GO compared to without GO, others have not found an association between Se status and GO severity or activity [14]. Confirmation and clarification of potential mechanisms for the effect in GO are therefore eagerly awaited.

We are probably not the only ones confronted with the statement: 'You may be right about a questionable efficacy, but Se is then at least harmless.' However, this is incorrect. There is much to suggest a U-shaped link with Se status; whereas supplementation may benefit people with low Se status, those with adequate-to-high status might be affected adversely and should not take supplements [1]. This, as a minimum, requires that basal levels in a given individual or population is known before ad- vocating Se supplementation. Recent studies have increasingly been focused on the potential side effects of Se, also when levels are within the ones reached by Se supplementation as low as 100-200 $\mu \mathrm{g}$ [15].

The current evidence of a clinically meaningful, costeffective, durable, and safe implementation of Se supplementation is very sparse. Current use, at least in Italy, is not based on evidence and may well be harmful. The article by Negro et al. [9] is timely, important, and frightening. It teaches us an important message. Not implementing evidence-based medicine, needless to say, is unacceptable. However, implementing therapy, which potentially may turn out to be harmful, and for which there is no evidence is, in our view, much worse. Ongoing prospective, randomized, long-term studies, in both Graves' disease [16] and chronic autoimmune thyroiditis [17], will provide some answers concerning the value of supplemental Se to antithyroid drugs and $\mathrm{LT}_{4}$, respectively. Until the data from these studies have been properly analyzed, and to avoid the risks of medical reversal [18], use of Se supplementation should be restricted to indications for which there is evidence, namely the correction of Se deficiency [1]. Also, should indications for Se supplementation emerge, much work remains in order to define subpopulations who will benefit the most, the type and dose of Se preparation, and length of therapy.

From the data provided by Negro et al. [9], and given that they are truly representative of what Italian patients are advised to take, a number of pertinent questions arise. How have specialists in thyroid diseases come to these recommendations? Who has the responsibility for implementing therapy that is not endorsed by any relevant authority? Who has the responsibility to reverse inadvertent practice patterns? In our view, while Italian physicians and other authorities disseminate recommendations based on evidence, the present questionnaire should be followed by an in-depth global investigation of current practice patterns. If the present Italian data are representative of a widespread and mostly inappropriate use of Se, all our thyroid societies and their members have an obligation to correct this and make it clear what the current recommendations are when facing our patients.

\section{Disclosure Statement}

The authors report no conflicts of interest. 


\section{References}

$>1$ Rayman MP: Selenium and human health. Lancet 2012;379:1256-1268.

$>2$ Wu Q, Rayman MP, Lv H, Schomburg L, Cui B, Gao C, Chen P, Zhuang G, Zhang Z, Peng X, Li H, Zhao Y, He X, Zeng G, Qin F, Hou P, Shi B: Low population selenium status is associated with increased prevalence of thyroid disease. J Clin Endocrinol Metab 2015;100: 4037-4047.

$\checkmark 3$ Köhrle J: Selenium and the thyroid. Curr Opin Endocrinol Diabetes Obes 2015;22: 392-401.

4 Winther KH, Bonnema SJ, Cold F, Debrabant B, Nybo M, Cold S, Hegedüs L: Does selenium supplementation affect thyroid function? Results from a randomized, controlled, doubleblinded trial in a Danish population. Eur J Endocrinol 2015;172:657-667.

5 Rasmussen LB, Schomburg L, Köhrle J, Pedersen IB, Hollenbach B, Hog A, Ovesen L, Perrild H, Laurberg P: Selenium status, thyroid volume, and multiple nodule formation in an area with mild iodine deficiency. Eur J Endocrinol 2011;164:585-590.

-6 Van Zuuren EJ, Albusta AY, Fedorowicz Z, Carter B, Pijl H: Selenium supplementation for Hashimoto's thyroiditis. Cochrane Database Syst Rev 2013;6:CD010223.

7 Wichman J, Winther KH, Bonnema SJ, Hegedüs L: Selenium supplementation significantly reduces thyroid autoantibody levels in patients with chronic autoimmune thyroiditis: a systematic review and meta-analysis. Thyroid, revision resubmitted.
8 Brix TH, Hegedüs L: Twin studies as a model for exploring the aetiology of autoimmune thyroid disease. Clin Endocrinol (Oxf) 2013; 76:457-464.

-9 Negro R, Attanasio R, Grimaldi F, Marcocci C, Guglielmi R, Papini E; on behalf of AME (Associazione Medici Endocrinologi) and AACE (American Association of Clinical Endocrinologists) Italian Chapter: A 2016 Italian survey about the clinical use of selenium in thyroid disease. Eur Thyroid J DOI: 10.1159/000447667.

10 Pilli T, Cantara S, Schomburg L, Cenci V, Cardinale S, Heid EC, Kuhn EC, Cevenini G, Sestini F, Fioravanti C, D'Hauw G, Pacini F: IFN $\gamma$-inducible chemokines decrease upon selenomethionine supplementation in women with euthyroid autoimmune thyroiditis: comparison between two doses of selenomethionine ( 80 or $160 \mu \mathrm{g}$ ) versus placebo. Eur Thyroid J 2015;4:226-233.

11 DeGroot L, Abalovich M, Alexander EK, Amino N, Barbour L, Cobin RH, Eastman CJ, Lazarus JH, Luton D, Mandel SJ, Mestman J, Rovet J, Sullivan S: Management of thyroid dysfunction during pregnancy and postpartum. An Endocrine Society clinical practice guideline. J Clin Endocrinol Metab 2013;97: 2543-2565.

12 Marcocci C, Kahaly GJ, Krassas GE, Bartalena L, Prummel M, Stahl M, Altea MA, Nardi M, Pitz S, Boboridis K, Sivelli P, von Arx G, Mourits MP, Baldeschi L, Bencivelli W, Wiersinga W; European Group on Graves' Orbitopathy: Selenium and the course of mild Graves' orbitopathy. N Engl J Med 2011;364:1920-1931.
13 Bartalena L, Baldeschi L, Boboridis K, Eckstein A, Kahaly GJ, Marcocci C, Perros P, Salvi M, Wiersinga WM; on behalf of the European Group on Graves' Orbitopathy (EUGOGO): The 2016European Thyroid Association/ European Group on Graves' Orbitopathy Guidelines for the Management of Graves' Orbitopathy. Eur Thyroid J 2016;5:9-26.

14 Dehina N, Hofmann PJ, Behrends T, Eckstein A, Schomburg L: Lack of association between selenium status and disease severity and activity in patients with Graves' ophthalmopathy. Eur Thyroid J 2016;5:57-64.

15 Jablonska E, Vinceti M: Selenium and human health: witnessing a Copernican revolution? J Environ Sci Health C Environ Carcinog Ecotoxicol Rev 2015;33:328-368.

$>16$ Watt T, Cramon P, Bjorner JB, Bonnema SJ, Feldt-Rasmussen U, Gluud C, Gram J, Hansen JL, Hegedüs L, Knudsen N, Bach-Mortensen P, Nolsøe R, Nygaard B, Pociot F, Skoog M, Winkel P, Rasmussen AK: Selenium supplementation for patients with Graves' hyperthyroidism (the GRASS trial): study protocol for a randomized controlled trial. Trials 2013;14:119.

17 Winther KH, Watt T, Bjørner JB, Cramon P, Feldt-Rasmussen U, Gluud C, Gram J, Groenvold M, Hegedüs L, Knudsen N, Rasmussen ÅK, Bonnema SJ: The chronic autoimmune thyroiditis quality of life selenium trial (CATALYST): study protocol for a randomized controlled trial. Trials 2014;15:115.

18 Prasad VK, Cifu AS: Ending Medical Reversal: Improving Outcomes, Saving Lives. Baltimore, John Hopkins University Press, 2015. 